\title{
Walking side-by-side: Recovery Colleges Revolutionising Mental Health Care
}

\begin{tabular}{|r|l|}
\hline Journal: & Mental Health and Social Inclusion \\
\hline Manuscript ID & MHSI-11-2017-0050 \\
\hline Manuscript Type: & Primary Research Paper \\
\hline Keywords: & $\begin{array}{l}\text { Recovery, Co-Production, Peer Education, Self-Determination, Service } \\
\text { Transformation }\end{array}$ \\
\hline \multicolumn{2}{|l}{} \\
\hline
\end{tabular}

\section{SCHOLARONE ${ }^{m}$ \\ Manuscripts}




\section{Walking side-by-side: Recovery Colleges Revolutionising Mental Health Care}

Title

Walking side-by-side: Recovery Colleges Revolutionising Mental Health Care

\section{Abstract \\ Purpose}

The Recovery College model is an innovative approach to providing education to consumers, carers and mental health staff, with the potential to facilitate both personal recovery gains and organisational transformation towards recovery-focused service provision. The purpose of this study was to explore the experiences of students who attended the South Eastern Sydney Recovery College (SESRC).

Design

An exploratory, descriptive qualitative design was employed with data collected through seven focus group interviews with consumers and mental health staff who had participated in courses run by the SESRC. Thematic analysis of the data was conducted using both deductive and inductive processes in order to interpret the data.

Findings

All participants were positive about their involvement in the RC. Four themes emerged from the thematic analysis: connection with others, hope for the future, the importance of the lived experience, and changing attitudes and systems.

Originality 
The outcomes of this study indicate that the SESRC is achieving its aims in relation to both personal recovery gains, and the potential to impact on service transformation. It highlights the centrality of co-production as a fundamental aspect of the Recovery College model. This paper contributes to the emerging evidence base for this model and provides evidence that this model is applicable to the Australian context.

\section{Introduction}

Recovery is the guiding philosophy for contemporary mental health services in Australia, as outlined in current key State and National documents (Commonwealth of Australia, 2009 and 2013; NSW Mental Health Commission, 2014). However, services struggle to integrate this paradigm, often adopting the philosophy without altering practice (Slade et al., 2012). A cultural shift is required, challenging the established hierarchies, from professionals as all-knowing experts to egalitarian relationships of shared power with service users (Shepherd et al., 2008; Slade et al., 2014). The Recovery College model has recently emerged as an approach with the potential to facilitate both personal recovery gains and organisational transformation towards recovery-focused services (Meddings et al., 2015b; Perkins et al., 2012).

This model transforms traditional mental health care into educational activities for mental health consumers, their carers and mental health staff. Through education Recovery Colleges help people develop their personal resources, become experts in their own care, and realise their life goals and aspirations. 


\title{
Benefits of Recovery College
}

Studies examining the impact of Recovery Colleges demonstrate a range of benefits to those who participate, including high satisfaction rates and positive experiences (Gill, 2014; Meddings et al., 2014a; Meddings et al., 2015a; Meddings et al., 2014b; Meddings et al., 2015b; Rinaldi and Suleman, 2012; Zucchelli and Skinner, 2013). Reported benefits to personal recovery include: increased hopefulness about the future, acquisition of new skills and knowledge, achievement of personal goals, and improvements in quality of life and wellbeing (Perkins et al., 2012; Meddings et al., 2015a; Meddings et al., 2014b; Meddings et al., 2015b). In addition, RCs increase social networks brought about by a sense of connection developed in an environment where students feel safe to share their experiences (Gill, 2014; Meddings et al., 2014b; Meddings et al., 2015b; Newman-Taylor et al., 2016).

\begin{abstract}
A fundamental aim of the RC model is instilling confidence and selfdetermination for people to manage their lives (Perkins et al., 2012). There is evidence that this is achieved, with people developing greater selfmanagement and control of their own recovery journeys (McGregor et al., 2014; Meddings et al., 2015a; Perkins et al., 2012). There is equivocal evidence regarding the success of RCs in facilitating pathways to education and employment (Meddings et al., 2015b; Rinaldi and Suleman, 2012).
\end{abstract}

\section{Transformational Change}

RCs not only result in gains to personal recovery, but also have the potential to facilitate transformational change within mental health services. Such 
potential is optimised when educational approaches are integrated with other aspects of mental health service provision (Meddings et al., 2015a; Perkins et al., 2012). When integrated, RCs have the potential to promote shifts in mindsets of mental health staff from a clinical to an educational orientation, prompt reflection on personal practice and motivate personal and professional change (Meddings et al., 2014a; Newman-Taylor et al., 2016; Zucchelli and Skinner, 2013). Health professionals involved in RCs increase their capacity to see strengths and potential, develop positive attitudes towards recovery and acquire new skills to support self-management. (McGregor et al., 2014; Meddings et al., 2015b; Rinaldi and Suleman, 2012; Zabel et al., 2016). Furthermore, RCs can impact on staff morale, with mental health staff involved as students in one $\mathrm{RC}$ reporting renewed motivation and a positive impact on their perception of the organisation (Zabel et al., 2016).

\section{South Eastern Sydney Recovery College}

The South Eastern Sydney Recovery College (SESRC), established in 2014, is the first example of a public health service operated Recovery College in Australia. The college operates in line with the guiding principles and defining features of RCs as outlined by Perkins et al. (2012) and McGregor et al. (2014). The program offers a curriculum of recovery based educational courses in partnership with local community colleges who provide adult education expertise and access to mainstream venues. Courses are codeveloped and co-facilitated by a peer educator and a clinical educator and attended by consumers, carers and mental health staff. These fundamental principles of co-production are highlighted throughout the $\mathrm{RC}$ literature and 
reported as a central factor in inspiring hope and optimism, with the colearning environment that includes service users and service providers learning side by side as equals noted as positive and helpful (Meddings et al., 2014b; Newman-Taylor et al., 2016; Perkins et al., 2012; Zabel et al., 2016). At an organisational level, the role of peer workers and the value of coproduction is challenging traditional ways of working and enabling changes in power dynamics (Gill, 2014; McGregor et al., 2014; Meddings et al., 2014a; Meddings et al., 2014b; Zucchelli and Skinner, 2013).

SESRC has undertaken a comprehensive evaluation strategy incorporating a mix of qualitative and quantitative methods. This paper reports one aspect of the evaluation, the results of a focus group study that investigated the experiences of people who participated in the college.

\section{Method}

This was an exploratory, qualitative study. The aim was to explore the experiences of consumers, carers, mental health clinicians and educators, in relation to their participation in the SESRC, both as teachers and learners.

\section{Data Collection}

Data were collected through focus group interviews with people who had participated in the initial courses run by SESRC. Focus groups interviews were selected because this means of data collection enabled information to be gathered from a variety of perspectives (Stalmeijer et al., 2014). Focus groups are an efficient and cost-effective method for collecting data from 
multiple participants, thus increasing the number of participants in a qualitative study. Because group interaction is socially oriented, a sense of belonging has the potential to enable participants to feel safe to share their thoughts and perceptions (Onwuegbuzie et al., 2009). Interviewing in a group offered the opportunity for participants to not only share what they were thinking but also respond to each other's ideas, thus provided an opportunity to explore similarities and differences in perspectives.

\section{Procedures}

Upon completion of their attendance, SESRC students (consumers, carers and clinicians) were invited to participate in a focus group interview to discuss their experiences of the college. An information sheet explaining the focus groups was provided. Those students who indicated willingness to participant in the focus groups provided contact details. Once contacted, they were scheduled into a focus group at a time that was suitable to them and the focus group moderator. The focus groups were moderated and audio taped by a peer researcher and a member of the research group (KG), who then transcribed the interviews verbatim. Use of a consumer/peer researcher supports the co-production philosophy of the college, thus creating the potential to produce a more nuanced and effective result (Newman-Taylor et al., 2016). Separate focus groups were conducted with consumers and clinical staff members, as the questions that were posed differed for these two groups. The interview schedules for the two groups are outlined in Table 1.

Insert table 1 


\section{Data Analysis}

Thematic analysis of the data was conducted both deductively and inductively (Elo and Kyngäs, 2008). Deductive analysis was undertaken by grouping the data according to the questions from the interview schedule. Inductive analysis was then carried out through open coding of the data and examining how answers to the interview questions could be clustered into related ideas and common threads. These ideas and threads then were assigned to categories that were further analysed for patterns and developed into themes. Thus, the final analysis was interpretive and thematic in nature (Crowe et al., 2015; Vaismoradi et al., 2013). The analyses were initially conducted independently by two authors external to the RC (KG and JSP). Their interpretations were compared and discussed with all authors until consensus was achieved in relation to the final themes.

\section{Ethical Considerations}

Fully informed, written consent was obtained for those students who agreed to be contacted and attended a scheduled focus. The study was approved by the affiliated university as low/negligible risk because it was deemed to be an evaluation of an educational strategy (UTS HREC 2014000300). Nonetheless, there was the potential risk of embarrassment during the focus group discussion. This was mitigated by assuring participants that no judgement was made about their expressed thoughts, and that they were free to withdraw at any time. 


\section{Results}

Seven focus group interviews were conducted with consumers and clinical staff who had been students and/or participated in the initial courses that were run by the SESRC. Sixteen consumers and thirteen staff participated in the interviews which occurred between January 2015 and May 2016. All of the consumers attended the College as students. Staff participants were involved in the development and delivery of the courses, attended as students and/or worked with consumers who attended the College.

All participants were positive about their involvement in the RC. Four themes emerged from the thematic analysis: connection with others, hope for the future, the importance of the lived experience, and changing attitudes and systems.

Sense of Connection with Others: Other people feel the same Participation in the college enabled consumers to experience camaraderie with other consumers, decreasing their sense of social isolation. The validation that they received from others helped them to appreciate that they were not alone. Knowing that others had similar experiences was both affirming and reassuring:

The whole notion of the RC makes you less insular makes you see you are not alone and there are a lot of other people in the same situation. (Consumer FG3) 
$[R C]$ encouraged me to be involved, reengage with people... It is not just about the education. (Consumer FG2)

Definitely helpful to have group environment makes you feel - part of society - feel comfortable and not left out. Not so alone. (Consumer FG4)

Clinical staff also were aware of the importance of the sense of connection that participation in the RC engendered:

People can look at their issues positively, so they can change and grow, and see from others that recovery is possible. (Staff FG1)

Many of my clients need more friends and want to socialise and it is a place where they can meet people who have been in similar situations, get support. (Staff FG2)

Hope, Inspiration, Self-Determination and Future Directions: Getting back my life

Most participants commented on the sense of hope that was instilled as a result of participating in the $\mathrm{RC}$. This was supported by mutual sharing and being with others who were on a recovery journey. In this sense, hope and inspiration were reinforced by a sense of connection with others. Consumers described how the RC gave them skills and confidence to manage their recovery and move beyond mental illness: 
The Recovery Colleges provided a sense of hope. It made me really excited. (Consumer FG2)

It helps me to see how far I have come. I found the creativity course helped me to regain the skills I had let go. (Consumer FG3)

They give you all the tools to enable you to help yourself, rather than just saying go to medical practitioner and get drugs. Definitely able to incorporate what I learned from the college into daily life. (Consumer FG4)

I have been waiting for a magic person to come out of the air to tell me what to do. RC is teaching me it has to come from me, not someone telling me what to do. (Consumer FG3)

This new-found confidence opened pathways to education and employment with participants setting work and study goals:

It opened my future; the future feels good to me. I set goals to volunteer or find a job. I feel more educated about it and I have more confidence with the opening of pathways. (Consumer FG2)

I feel worthwhile now, as opposed to when I got out of hospital, I felt worthless. I am doing these courses as one of the things I am striving 
to be is a peer support worker so it was helpful to see peer educators. (Consumer FG3)

I feel like RC helped me get jobs. (Consumer FG3)

Consumers were grateful for the ongoing goal-setting process that was embedded into the structure of the RC. This enabled them to map out their preferred journey in recovery and develop concrete plans to achieve their goals:

Set short term and long-term goals, and now have the belief that I can get better and have a better life. (Consumer FG2)

Setting plans to get back to life through goal setting. When I work through the goals I feel I can get back my life, and believe I will get there. (Consumer FG2)

Staff also recognised the importance of the $\mathrm{RC}$ in inspiring hope and providing knowledge and skills to assist consumers in meeting their life goals and moving towards self-determination:

They [consumers] gain determination and motivation (Staff FG1)

When we talk about recovery and strengths people say they really wish they had heard about these things ten years ago. People say it has 
given them hope, and it has changed, we have had a lot of feedback like this (Staff FG2)

Importance of the Lived Experience: Humanise the experience It was predominately clinical staff who commented on the importance of involving people with lived experience of mental health concerns in the processes of co-facilitation and co-learning. They highlighted the inspiring role of the peer educator and the creation of a safe space for the sharing of stories:

It is wonderful to work with consumers, they bring a unique spirit, depth and breadth to the course. The consumer facilitators humanise the learning, and make the environment safe for other consumers to share lived experiences. (Staff FG1)

I have had very positive feedback from participants, extremely positive. They see it is an inspiration... Very powerful - they do see the peer educators as a powerful role model, especially with the resilience course they can see it. (Staff FG2)

[RC] has made us more mindful that the lived experience is a knowledge base that needs to be tapped into. (Staff FG2)

Consumers also valued the inclusion of both them and clinical staff as students sitting side-by side as equals in the RC experience: 
By incorporating professionals into courses, they walk away with the lived experience, and can sympathise with the lived experience, and learn what the person with the lived experience has to deal with on a daily basis (Consumer FG1)

Changing Attitudes and Systems: Change the dynamics of things

Experience with the RC helped to shape both consumer and staff attitudes through a renewed and deepened understanding of the meaning of recovery. Consumer students described the life changing impact of the RC on their thinking and understanding:

$R C$ changed my meaning of recovery. It changed me absolutely (Consumer FG2)

Recovery College has definitely changed me, l'm thinking differently. It has had a very positive impact. The peer worker changed me...it was like my head went BOOM! (Consumer FG1)

I hadn't thought that much about recovery before I came across Recovery College. ... I started looking at recovery, and looked at the personal journey of people, defined differently. (Staff FG2)

Many staff described how this new insight into recovery was having an impact on their clinical practice. They described relinquishing judgemental and 
controlling attitudes and focusing on the facilitation of consumer choice and decision making:

For a clinician, it makes you realise that what you think is best for people, might not be, and to see that people are on their journey. ... We need a less parental approach. (Staff FG2)

It helps me to let go, when I am aware that I am not letting go enough. Give them the information they need and then step back. (Staff FG2)

It helps people check in on values in delivery of care. In being a costudent with consumers, carers, staff - have to be really aware of power dynamics in the room ... I have found that it has helped me to be non-judgemental in my work. (Staff FG2)

Some staff described how understanding recovery challenges the dominant biomedical model that focuses on deficits rather than strengths. They recognised that incorporating a recovery philosophy into practice requires changes to current systems through shifting the orientation from one of dependency to that of autonomy and self-determination.

$R C$ provides for clinicians a designated space for focusing on recovery language ... it is still a medical model focus and still has deficit based language system ... RC provides a space to recheck our values and to 
be reminded to keep thinking about recovery in what can be a challenging workplace (Staff FG2)

It is difficult to change attitudes when the focus has been so long on the medical model of treatment... patient feels excluded from care plan and management ... and this is why we see the revolving door because we haven't agreed on what they see as recovery (Staff FG2)

Participants appreciated that the RC was a vehicle for challenging stigma and raising awareness of the importance of altering attitudes about mental health care. They recognised that the $\mathrm{RC}$ has the potential to reform existing systems of mental health care by challenging existing power dynamics.

Working in tandem, together. Work in partnership with professionals (Consumer FG1)

Breaks down stigma, revolutionising mental health care. It is walking side-by-side with people, rather than dragging them along (Staff FG1)

Working on an inpatient unit we could go a lot further with autonomy and recovery, so this reinforced my ideas that we could go a lot further (Staff FG2)

Having a flat structure, removing the power imbalances and hierarchy. I like how the co-production model works (Staff FG2) 
Autonomy is really important, if I think I am working in a coercive system it makes me uneasy, but if I can see the system changing it makes it easier for me to do my job (Staff FG2)

When consumers facilitate they give a voice to the learners, it challenges the power. The power imbalance was gone. (Staff FG2)

\section{Discussion}

The outcomes of this study indicate that the SESRC is achieving its aims. More importantly, the results support findings from similar studies of RCs in relation to both personal recovery gains, and the potential impact on service transformation (Meddings et al., 2015b; Newman-Taylor et al., 2016; Perkins et al., 2012).The high levels of satisfaction and positive feedback are consistent with the literature, thus indicating that both consumers and clinicians who participate as students in the SESRC value the unique approach (Gill, 2014; Meddings et al., 2014a; Meddings et al., 2015b; Zucchelli and Skinner, 2013).

A sense of connection with others has been reported by both consumers and mental health staff as a key benefit to consumers who are RC students (Meddings et al., 2014b; Newman-Taylor et al., 2016). This study confirms that participation in a RC achieves social benefits, thus reducing the social isolation experienced by mental health consumers. 
The sense of hope and inspiration that people gained from participating is notable, as promoting hopefulness is core component of recovery (Leamy et al., 2011) and a fundamental aim of RCs. Consumers described how hopefulness led to newly found confidence in taking personal responsibility for their own recovery, with staff also identifying this as moving towards selfdetermination, another core element of recovery (Farkas et al., 2005; Slade et al., 2014). With fresh hope, people felt more optimistic about the future and able to pursue their ambitions, particularly in areas of work and study.

There is interest internationally in whether the RC model can facilitate pathways to open study and employment however there is insufficient evidence available as yet to determine this (Meddings et al., 2015b). In this study, many students reported developing confidence in setting and pursuing work and study goals with some directly attributing their success in gaining employment to their participation in the $\mathrm{RC}$. The importance that consumers placed on structured goal setting in creating vocational and other opportunities highlights the value of peer-facilitated life planning, another core constituent in RCs (McGregor et al., 2014). The success of this process is contingent on the individualised goal setting approach adopted by the College.

The importance of lived experience incorporated through the processes of coproduction and co-learning emerged as a central theme in the current study, in line with the RC literature (McGregor et al., 2014; Meddings et al., 2014a; Meddings et al., 2015b; Zabel et al., 2016; Zucchelli and Skinner, 2013). The 
value of peer involvement, emphasised by study participants, highlights the centrality of co-production in the RC model. The integration of the lived experience of consumers or peers with the expertise of professionals to provide recovery based mental health education that is co-designed and codelivered recognises the benefit of equal and reciprocal relationships (Slay and Stephens, 2013). Some people emphasised the importance of the peer educator role whilst others appreciated the balance of having both peer and clinical educators. Co-production was important to both consumer and staff students however it was the staff who predominantly emphasised the inspiring role of the peer educator and the added perspectives they bring, both in relation to their experiences as students and as clinical educators. Additionally, participants valued the process of co-learning, with consumers, carers and mental health staff participating side by side as students.

The findings related to co-production illustrate the effectiveness of the RC approach in influencing staff attitudes by helping them to acknowledge the value of the lived experience knowledge base. The study provided evidence that this creates possibilities for changing attitudes and transforming the mental health system. This supports the RC literature that describes how the inherent modelling of transformed relationships between service users and mental health practitioners challenges the 'us and them' culture and acts as a catalyst for changing conventional roles, embracing recovery values and tackling the stigma and discrimination present within the mental health system itself (Gill, 2014; McCaig et al., 2014; Newman-Taylor et al., 2016; Perkins et al., 2012; Skipper and Page, 2015; Zabel et al., 2016). 
In the present study, both consumers and staff described their deepening understanding of recovery and profound changes in their thinking and understanding. Staff in particular gained new insight into the nature of recovery and described an internal shift towards a more respectful, nonjudgemental and collaborative approach in working with consumers.

Furthermore, staff identified the positive impact this way of working can have on their satisfaction and morale, supporting the recent findings by Meddings et al., (2014a) and Zabel et al. (2016).

This shifting of attitudes towards new ways of working provides impetus for change in the mental health system itself and a re-orientation toward recovery. In the United Kingdom, RCs have been positioned as central to driving recovery focused organisational change (Perkins et al., 2012). Nonetheless, study participants also recognised challenges they perceived in achieving these changes, especially in relation to the entrenchment of the biomedical model of care. Challenges such as these faced by mental health services to achieve the culture change required for a true recovery orientation are widely reported in the literature (Shepherd et al., 2010; Shepherd et al., 2008; Slade et al., 2012; Slade et al., 2014). The Recovery College model offers a framework that can successfully facilitate this transformation, with the current study providing evidence that this is applicable to the Australian context. 


\section{Strengths and Limitations}

Participants who volunteered to contribute to the focus groups may have been those with a positive experience of the $\mathrm{RC}$, and are therefore may not a representative sample. In qualitative research, generalisability is not the aim, but rather to gain insight and understanding into phenomena. In this respect, the findings add to a deeper understanding of the experience of RC participants.

As this was an exploratory qualitative study, generalisability is not possible. However, the findings are well-supported in the literature and therefore can be transferred to other settings.

Staff and consumers were interviewed in separate focus groups, limiting the possibility of disclosing divergent viewpoints. Nonetheless, having only consumers in a group may have led to greater expression of negative views about services and less fear of potential reprisal.

\section{Implications for future research}

The promise of RCs in bringing about culture change in mental health services has yet to be fully realised. Research into their actual impact on clinical practice is warranted. The benefits to consumers of participating in RCs needs to be quantified in relation to recovery gains such as employment and social inclusion. 
Fiscal cost-benefit analyses of RCs are needed in order to convince decisionmakers of the benefits of introducing such services. The cost-benefit decisions will be challenged in activity-based costing structures, as participation in RCs may lead to less dependence of consumers on mainstream services. 


\section{References}

Commonwealth of Australia, (2009), Fourth National Mental Health Plan: an agenda for collaborative government action in mental health 20092014, Commonwealth of Australia, Canberra.

Commonwealth of Australia, (2013), A National Framework for Recovery Oriented Mental Health Services, Commonwealth of Australia, Canberra.

Crowe, M., Inder, M. and Porter, R. (2015), "Conducting qualitative research in mental health: Thematic and content analyses", Australian \& New Zealand Journal of Psychiatry, Vol. 49, No. 7, pp. 616-623.

Elo, S. and Kyngäs, H. (2008), "The qualitative content analysis process", Journal of Advanced Nursing, Vol. 62, No. 1, pp. 107-115.

Farkas, M., Gagne, C., Anthony, W. and Chamberlin, J. (2005), "Implementing Recovery Oriented Evidence Based Programs: Identifying the Critical Dimensions", Community Mental Health Journal, Vol. 41, No. 2, pp. 141-158.

Gill, K. (2014), "Recovery College: Co-Production in Action: The Value of the Lived Experience in Learning and Growth for Mental Health", Health Issues, Vol. 113, pp. 10-14.

Leamy, M., Bird, V., Le Boutillier, C., Williams, J. and Slade, M. (2011), "Conceptual framework for personal recovery in mental health: systematic review and narrative synthesis", The British Journal of Psychiatry, Vol. 199, No. 6, pp. 445-452. 
McCaig, M., McNay, L., Marland, G., Bradstreet, S. and Campbell, J. (2014), "Establishing a recovery college in a Scottish University", Mental Health and Social Inclusion, Vol. 18, No. 2, pp. 92-97.

McGregor, J., Repper, J. and Brown, H. (2014), "The college is so different from anything I have done. A study of the characteristics of Nottingham Recovery College", The Journal of Mental Health Training, Education and Practice, Vol. 9, No. 1, pp. 3-15.

Meddings, S., Byrne, D., Barnicoat, S., Campbell, E. and Locks, L. (2014a), "Co-delivered and co-produced: creating a recovery college in partnership", The Journal of Mental Health Training, Education and Practice, Vol. 9, No. 1, pp. 16-25.

Meddings, S., Campbell, E., Guglietti, S., Lambe, H., Locks, L., Byrne, D. and Whittington, A. (2015a), "From Service User to Student - The Benefits of Recovery College", Clinical Psychology Forum, Vol. 268, pp. 32-37.

Meddings, S., Guglietti, S., Lambe, H. and Byrne, D. (2014b), "Student perspectives: recovery college experience", Mental Health and Social Inclusion, Vol. 18, No. 3, pp. 142-150.

Meddings, S., McGregor, J., Roeg, W. and Shepherd, G. (2015b), "Recovery colleges: quality and outcomes", Mental Health and Social Inclusion, Vol. 19, No. 4, pp. 212-221.

Newman-Taylor, K., Stone, N., Valentine, P., Hooks, Z. and Sault, K. (2016), "The Recovery College: A unique service approach and qualitative evaluation", Psychiatric Rehabilitation Journal, Vol. 39, No. 2, pp. 187. 
NSW Mental Health Commission, (2014), Living Well: A Strategic Plan for Mental Health in NSW 2014-2014, NSW Mental Health Commission, Sydney.

Perkins, R., Repper, J., Rinaldi, M. and Brown, H. (2012), Recovery Colleges: Implementing Recovery through Organisational Change, Mental Health Network NHS Confederation, Centre for Mental Health, London.

Rinaldi, M. and Suleman, M. (2012), "Care coordinators attitudes to selfmanagement and their experience of the use of the South West London Recovery College", unpublished, South West London and St. George's National Health NHS Trust, London.

Shepherd, G., Boardman, J. and Burns, M. (2010), Implementing Recovery: a methodology for organisational change, Sainsbury Centre for Mental Health, London.

Shepherd, G., Boardman, J. and Slade, M. (2008), Making Recovery a Reality, Sainsbury Centre for Mental Health, London.

Skipper, L. and Page, K. (2015), "Our recovery journey: two stories of change within Norfolk and Suffolk NHS Foundation Trust", Mental Health and Social Inclusion, Vol. 19, No. 1, pp. 38-44.

Slade, M., Adams, N. and O'Hagan, M. (2012), "Recovery: Past progress and future challenges", International Review of Psychiatry, Vol. 24, No. 1, pp. 1-4.

Slade, M., Amering, M., Farkas, M., Hamilton, B., O'Hagan, M., Panther, G. and Whitley, R. (2014), "Uses and abuses of recovery: implementing recovery-oriented practices in mental health systems", World Psychiatry, Vol 13, No. 1, pp. 12-20. 
Slay, J. and Stephens, L. (2013), Co-production in mental health: A literature review, new economics foundation, London.

Stalmeijer, R., McNaughton, N. and Van Mook, W. (2014), "Using focus groups in medical education research: AMEE guide no. 91", Medical Teacher, Vol. 36, No. 11, pp. 923-939.

Zabel, E., Donegan, G., Lawrence, K. and French, P. (2016), "Exploring the impact of the recovery academy: a qualitative study of Recovery College experiences", The Journal of Mental Health Training, Education and Practice, Vol. 11, No. 3, pp. 162-171.

Zucchelli, F. A. and Skinner, S. (2013), "Central and North West London NHS Foundation Trust's (CNWL) Recovery College: the story so far ...", Mental Health and Social Inclusion, Vol. 17, No. 4, pp. 183-189. 
Table 1: Interview Schedules

\begin{tabular}{|c|c|}
\hline Consumer Focus Groups & Staff Focus Groups \\
\hline $\begin{array}{l}\text { What has been your experience with the } \\
\text { Recovery College? }\end{array}$ & $\begin{array}{l}\text { What has been your experience with the } \\
\text { Recovery College? }\end{array}$ \\
\hline $\begin{array}{l}\text { What did you learn by participating in the } \\
\text { Recovery College? }\end{array}$ & $\begin{array}{l}\text { How has participating in Recovery } \\
\text { College changed your understanding of } \\
\text { recovery? }\end{array}$ \\
\hline $\begin{array}{l}\text { How has participating in the Recovery } \\
\text { College assisted you to... } \\
\text { - feel connected with other people? } \\
\text { - self-manage and take control of } \\
\text { - your life? } \\
\text { move beyond mental illness and } \\
\text { - gental health services? } \\
\text { - gain a sense of hope and identity? } \\
\text { in life? }\end{array}$ & $\begin{array}{l}\text { What changes have you noticed in } \\
\text { consumers with whom you are working } \\
\text { who have attended Recovery College? }\end{array}$ \\
\hline $\begin{array}{l}\text { How has participating in Recovery College } \\
\text { changed your personal meaning of } \\
\text { recovery? }\end{array}$ & $\begin{array}{l}\text { What are the benefits of Recovery } \\
\text { College? }\end{array}$ \\
\hline $\begin{array}{l}\text { Would you recommend Recovery College } \\
\text { to other people? }\end{array}$ & $\begin{array}{l}\text { Would you recommend Recovery College } \\
\text { to other people, especially consumers } \\
\text { with whom you are working? }\end{array}$ \\
\hline
\end{tabular}

